\title{
PENCATATAN ANGGARAN REALISASI PENGELUARAN ATK PADA KUA KECAMATAN TANAH JAWA KABUPATEN SIMALUNGUN
}

\author{
Mutia Rahma Laily ${ }^{1}$, Dedi Suhendro ${ }^{2}$, Anggi Ramadani ${ }^{3}$ \\ Program Studi Komputerisasi Akuntansi \\ AMIK Tunas Bangsa Pematang Siantar \\ mutiarahmalaily@gmail.com 1 \\ dedi.su@amiktunasbangsa.ac.id ${ }^{2}$ \\ anggir843@gmail.com ${ }^{3}$
}

\begin{abstract}
Abstrak
Abstrak - Proses pencatatan anggaran dan realisasi pengeluaran Alat Tulis Kantor (ATK) pada Kantor Urusan Agama (KUA) Kecamatan Tanah Jawa kabupaten Simalungundicatat secara manual dengan menggunakan bukti transaksi seperti kwitansi yang dipindahkan kedalam buku besar yang membuat proses pelaporan kurang efektif dan efisien. Maka, Penulis merancang sebuah sistem dengan mengunakan Bahasa Pemrograman Microsoft Visual Studio 2010 dan database mySQL untuk mengatasi masalah yang ada yang hanya dapat digunakan pada Kantor Urusan Agama Kecamatan Tanah Jawa kabupaten Simalungun dalam pengolahan data Alat Tulis Kantor (ATK). Metode perancangan sistem yang digunakan penulis yaitu DFD, ERD, Normalisasi, dan RAT untuk menghasilkan laporan ATK yang lebih efektif dan efisien.
\end{abstract}

Kata Kunci : microsoft visual basic 6.0, database mysql, ATK

\section{Pendahuluan}

Perkembangan ilmu pengetahuan dan teknologi yang pesat sekarang ini, membuat kita harus lebih membuka diri dalam menerima perubahan - perubahan yang terjadi akibat kemajauan dan perkembangan tersebut.Dalam masa persaingan yang sedemikian ketatnya sekarang ini, Sumber Daya Manusia (SDM) merupakan modal utama dalam suatu usaha, maka kualitas 
tenaga kerja harus lebih dikembangkan. Kantor Urusan Agama (KUA) Kecamatan Tanah Jawa kabupaten Simalungun adalah kantor yang melaksanakan sebagian tugas kantor Kementrian Agama Indonesia di kabupaten dan kota di bidang urusan agama Islam dalam wilayah kecamatan. Pada Kantor Urusan Agama Kecamatan Tanah Jawa kabupaten Simalungun, memliki lima bagian kerja yaitu, bagian kepala, bagian pengolahan bahan administrasi kepenghuluan, bagian penghulu, bagian operator dan bagian pegawai pembantu pencatat nikah (P3N).

Alat Tulis Kantor (ATK) merupakan salah satu faktor penunjang kegiatan operasional setiap harinya yang berperan dalam penyelesaian tugas para pegawai.Dengan ini, maka terdapat anggaran untuk Alat Tulis Kantor yang harus dikeluarkan setiap bulan yang berasal dari DIPA KEMENAG Kabupaten Simalungun. Namun, pada Kantor Urusan Agama Kecamatan Tanah Jawa kabupaten Simalungun proses pencatatan beban pengeluaran Alat Tulis Kantor (ATK) masih dicatat secara manual pada buku besar dengan tanda bukti kwitansi yang dihitung setiap bulan. Hal ini terjadi karena belum tersedianya program pencatatan untuk beban pengeluaran di Kantor Urusan Agama (KUA) Kecamatan Tanah Jawa kabupaten Simalungun sehingga dapat terjadi kesilapan dalam mencatat, dapat membuat berkas tercecer dan dapat mengakibatkan lamanya proses laporan di akhir bulan.

Konsep dasar sistem diungkapkan bahwa, "Sebuah sistem terdiri atas bagian-bagian atau komponen yang terpadu untuk suatu tujuan. Model dasar dari bentuk sistem ini adalah adanya masukan, pengolahan, dan keluaran."(Lestari and Irawan 2017).

Salah satu kebutuhan yang sangat penting bagi suatu organisasi saat ini adalah Teknologi Informasi (TI). Hal ini dikarenakan teknologi informasi dapat membantu perusahaan/organisasi itu sendiri.(Nugraha, Winaryo, and Fatta 2018).

Sistem adalah kumpulan atau himpunan dari unsur atau variabel-variabel yang saling terkait, saling berinteraksi, dan tergantung satu sama lain untuk mencapai tujuan.(Putri and Putra 2018). 
MySQL (My Structure Query Language) adalah sebuah software database, yang merupakan tipe data relasional yang artinya MySQL penyimpanan datanya dalam bentuk tabel-tabel yang saling berhubungan.(Sitohang 2018).

Sistem pencatatan ini memiliki fungsi sebagai berikut:

1. Menyediakan informasi tentang pencatatan anggaran dan realisasi beban pengeluaran alat tulis kantor pada Kantor Urusan Agama Kecamatan Tanah Jawa kabupaten Simalungun.

2. Membantu mempermudah proses pencatatan beban pengeluaran Alat Tulis Kantor (ATK) pada Kantor Urusan Agama Kecamatan Tanah Jawa kabupaten Simalungun.

3. Mempercepat proses pencarian data dan laporan yang berkaitan dengan Alat Tulis Kantor (ATK).

\section{Metode Penelitian}

Sistem Basis Data (Database System) adalah suatu sistem yang terdiri dari koleksi data atau kumpulan data yang saling berhubungan sedemikian rupa sehingga dapat mudah disimpan, diakses dan dikelola sehingga menghasilkan data optimal yang diperlukan pengguna.basisdata adalahHimpunan kelompok data (arsip) yang saling berhubungan yang diorganisasi sedemikian rupa agar kelak dapat dimanfaatkan kembali dengan cepat dan mudah. Basisdata juga dapat diartikan sebagai kumpulan data yang saling berhubungan yang disimpan secara bersama sedemikian rupa dan tanpa pengulangan (redundansi) yang tidak perlu, untuk memenuhi berbagai kebutuhan(Dwi Puspitasari 1, Cahya Rahmad 2 2016).

Dengan perancangan database diharapkan dapat mempermudah penyelesaian masalah dan kendala dalam pencatatan anggaran dan realisasi beban pengeluaran Alat Tulis Kantor (ATK) pada Kantor Urusan Agama Kecamatan Tanah Jawa kabupaten Simalungun.Sebelum perancangan penulis terlebih dahulu mengumpulkan variabel yang relevan dengan permasalahan yang terdapat pada Kantor Urusan Agama (KUA) Kecamatan Tanah Jawa kabupaten Simalungun khususnya bagian administrasi dan pembendaharaan. 


\section{Metode Pengumpulan Data}

Dalam penelitian ini penulis melakukan metode pengumpulan data yang erupakan suatu cara untuk pengambilan contoh data yang akan digunakan. Tekhnik yang dilakukan antara lain:

1. Observasi

Penulis mengadakan pengamatan langsung untuk pengambilan data Alat Tulis Kantor (ATK) pada Kantor Urusan Agama Kecamatan Tanah Jawa kabupaten Simalungun.

2. Wawancara

Dengan mengadakan tanya jawab kepada para pegawai, khususnya bagian bendahara merupakan cara pengumpulan data yang didapat oleh penulis.

3. Studi kepustakaan

Tekhnik ini dilakukan dengan melihat data pada lemari arsip yang berhubungan dengan judul.

\section{Rancangan Database}

Perancangan Sistem: merancang output, input, struktur file, program, prosedur, perangkat keras dan perangkat lunak yang diperlukan untuk mendukung sistem informasi (Agungsr 2011).

"Anggaran adalah rencana aktivitas bisnis jangka pendek, yang biasanya 12 bulan meliputi pengordinasian secara rinci rencana perusahaan yang diharapkan selama periode yang dianggarkan". (Suhendro and Aprilia 2017).

Database adalah suatu kelompok informasi yang terkait dalam suatu system pengelolahan data sehingga menghasikan suatu informasi yang cepat dan benar. Dalam hal ini database merupakan alat yang membantu pengarsipan dengan cara komputerisasi, sehingga tempat, waktu dan biaya lebih hemat, karena file-file yang diarsipkan dapat discan dan kemudian dapat disimpan di komputer, dengan menggunakan source pada unit Program Studi Administrasi Bisnis.(Wahyudi 2018).

Data Flow Diagram (DFD) disebut juga dengan Diagram Arus Data (DAD). DFD adalah: suatu model logika data atau proses yang dibuat untuk menggambarkan: darimana asal data, dan kemana tujuan data yang keluar dari sistem, dimana data 
disimpan, proses apa yang menghasilkan data tersebut, dan interaksi antara data yang tersimpan, dan proses yang dikenakan pada data tersebut (Afyenni 2014).

Dalam langkah perancangan basis data, tampilan anggaran dan realisasi pengeluaran Alat Tulis Kantor (ATK) berbasis bahasa pemrograman visual studio 2010 dan MySQL sebagai berikut:

\section{Perancangan DFD Level 0}

Adapun perancangan DFD Level 0 pada sistem pencatatan anggaran dan realisasi beban pengeluaran Alata Tulis Kantor (ATK) pada Kantor Urusan Agama Kecamatan Tanah Jawa kabupaten Simalungun seperti gambar berikut:

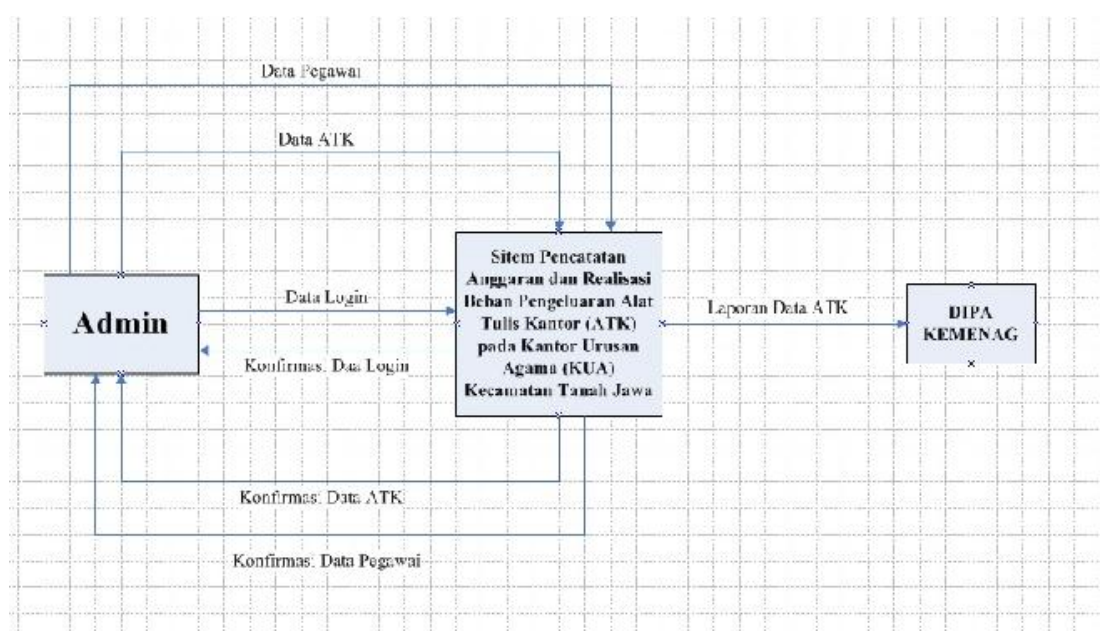

Gambar 1. Rancangan DFD Level 0

Dari gambar di atas terlihat bahwa Adminmelakukan pengisian data untuk masuk ke dalam sistem lalu Adminmenginputkan data dan mengelolahnya ke dalam sistem atau output eksekusi program ditunjukkan kepada DIPA KEMENAG yang berupa laporanlaporan. DIPA KEMENAG tidak bisa menggantikan kerja Admin karena dalam sistem ini DIPA KEMENAG hanya sebagai penerima laporan. 
2. Perancangan DFD Level 1

Adapun perancangan DFD level 1 dari Sistem PencatatanData Alat Tullis Kantor (ATK) milik Negara di Kantor Urusan Agama (KUA) Kecamatan Tanah Jawakabupaten Simalungun aadalah seperti gambar berikut ini:

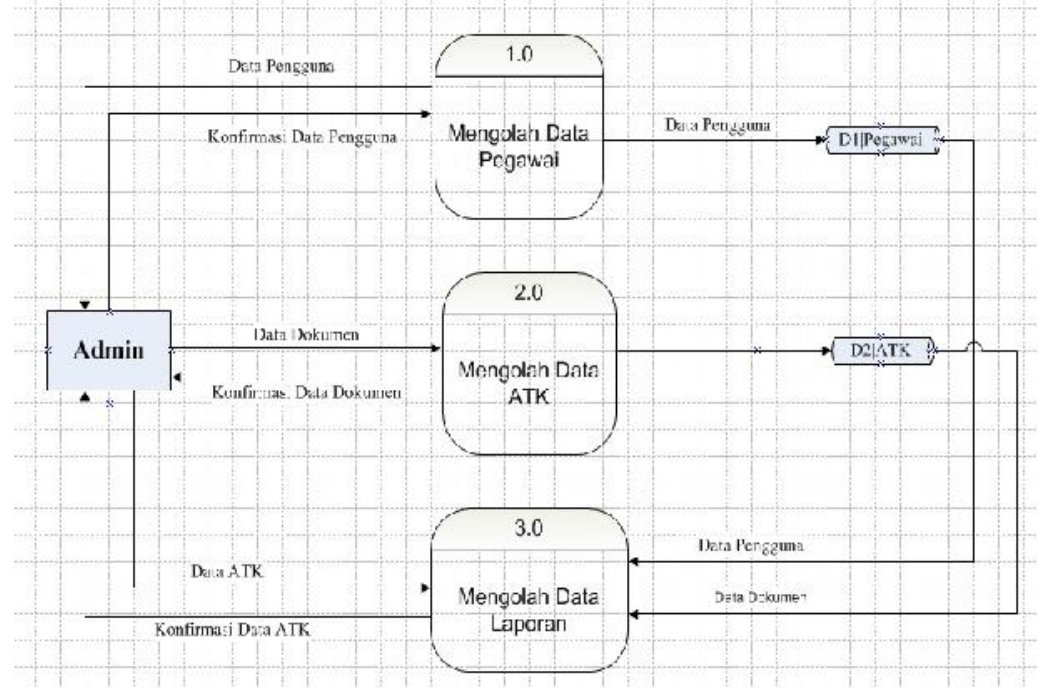

Gambar 2. DFD Level 1

3. Entity Relational Diagram

Bentuk dari Entity Relational Diagram dari Sistem PencatatanData Alat Tullis Kantor (ATK)Milik Negara Pada Kantor Urusan Agama (KUA) Kecamatan Tanah Jawakabupaten Simalungun adalah seperti gambar di bawah ini: 


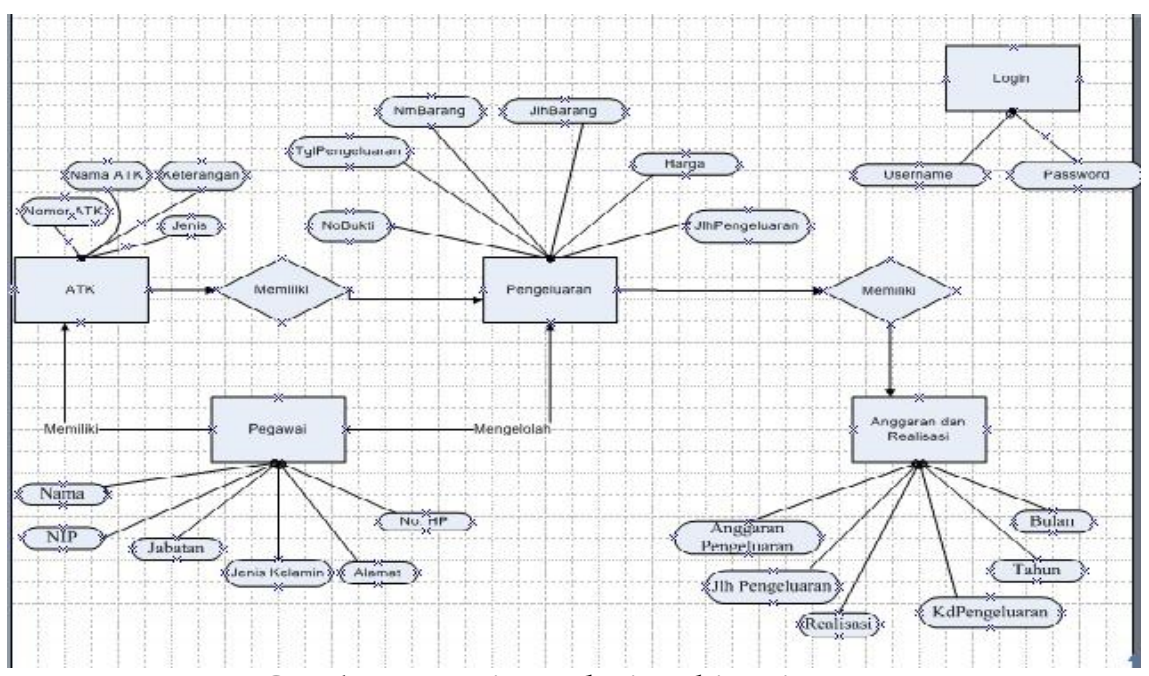

Gambar 3. Entity Relationship Diagram

\section{Rancangan Sistem}

Merupakan rancangan Sistem Pencatatandata Alat Tullis Kantor (ATK)milik negara Pada Kantor Urusan Agama (KUA) Kecamatan Tanah Jawakabupaten Simalungunyang dimodelkan dengan flowchart dibawah ini. 


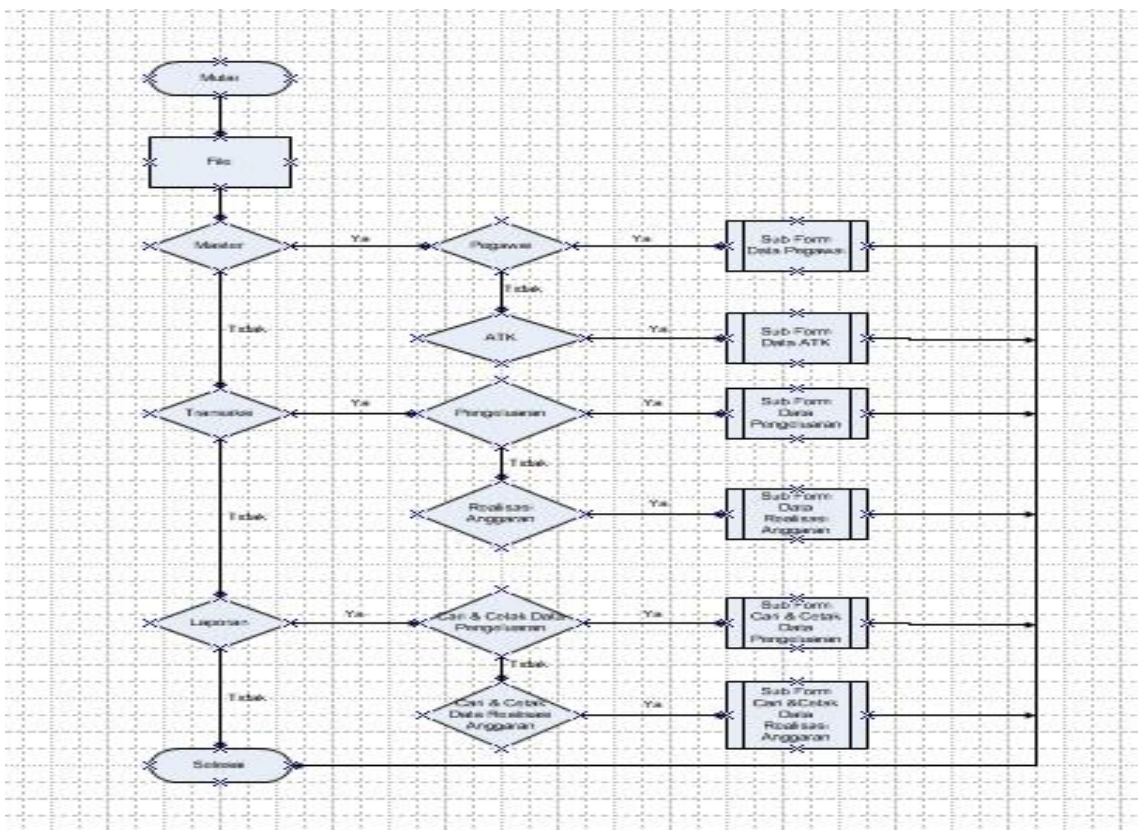

Gambar 4. Rancangan Sistem Flowcart

\section{Hasil dan Pembahasan}

Tampilan hasil perancangan dari Sistem Pencatatan Anggaran dan Realisasi Pengeluaran Alat Tuis Kantor (ATK) pada Kantor Urusan Agama Kecamatan Tanah Jawa kabupaten Simalungun yang dibuat oleh penulis sebagai berikut:

\section{A. Rancangan Masukan (Input)}

\section{Form Login}

Login digunakan untuk masuk kedalan sistem, yaitu dengan memasukkan username dan password dengan benar.Jika username dan password sesuai dengan sistem, maka user dapat membuka sistem. Tampilan login dapat dilihat pada gambar dibawah ini: 


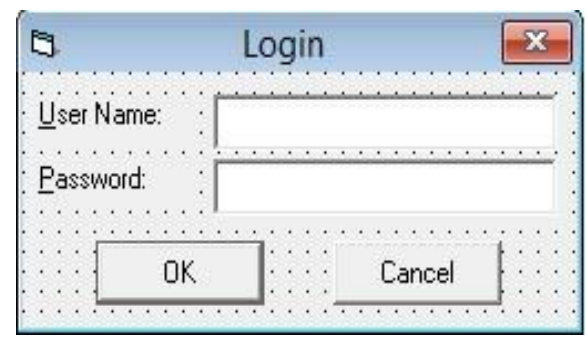

Gambar 5. Tampilan Menu Login

\section{Menu Utama}

Menu digunakan agar user dapat mengakses form - form yang diinginkan, Menu yang ada sesuai dengan hak akses user yang telah ditentukan pada saat login. Seperti pada gambar berikut :

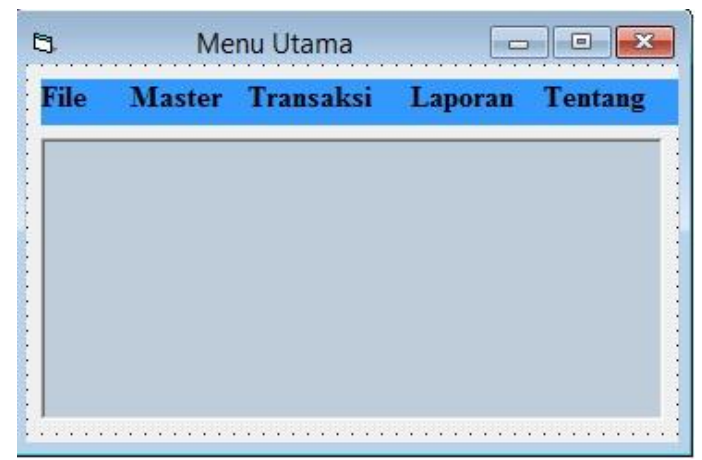

Gambar 6. Tampilan Menu Utama

\section{Form Anggaran}

Form anggaran untuk mencatat jumlah anggaran setiap bulan yang diberikan oleh DIPA KEMENAG pada Kantor Urusan Agama (KUA) Kecamatan Tanah Jawa kabupaten Simalungun untuk keperluan Alat Tulis Kantor (ATK). Tampilan form anggaran dapat dilihat pada gambar dibawah ini: 


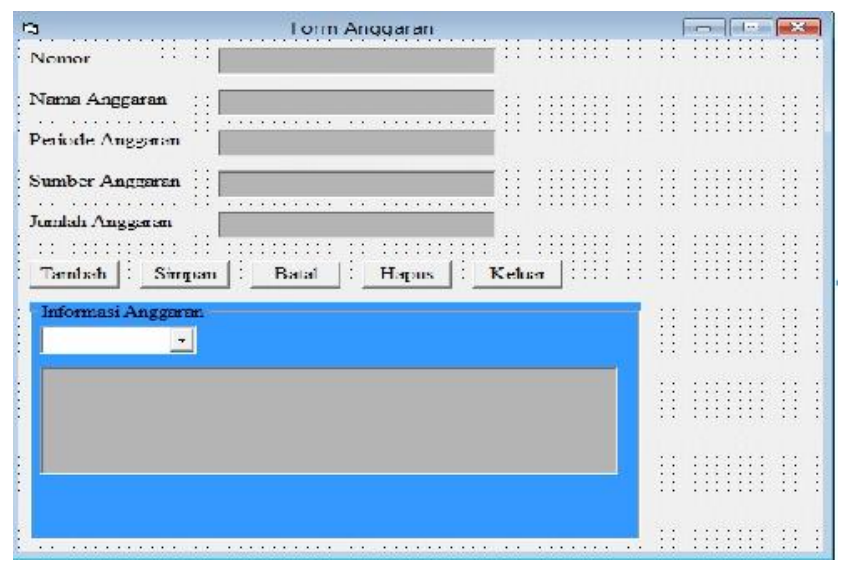

Gambar 7. Tampilan Form Anggaran

\section{Form Barang}

Form barang berfungsi untuk mencatat barang yang akan dibeli dengan menggunakan jumlah anggaran dan memudahkan pemakai untuk pengecekan barang yang diperlukan. Tampilan form barang dapat dilihat pada gambar dibawah ini:

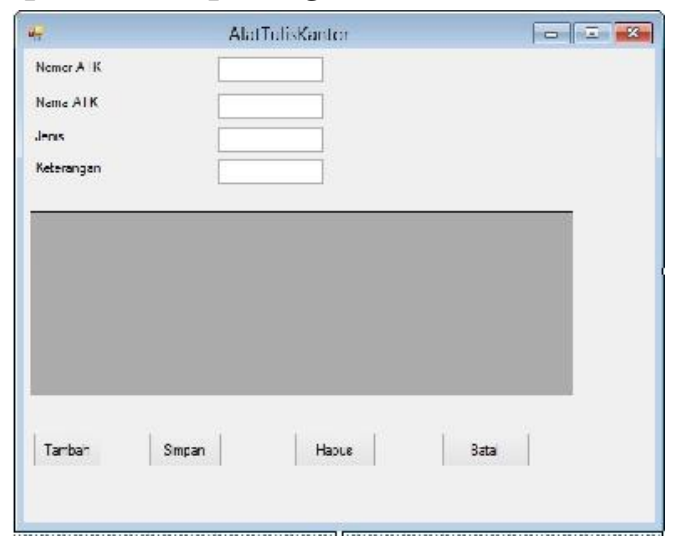

Gambar 8. Tampilan Form Barang

\section{Form Pegawai}

Form Pegawai berfungsi untuk mencatat data Pegawai yang akan diinput dengan menggunakan jumlah anggaran dan 
memudahkan untuk pengecekan barang yang catat. Tampilan form Pegawai dapat dilihat pada gambar dibawah ini:

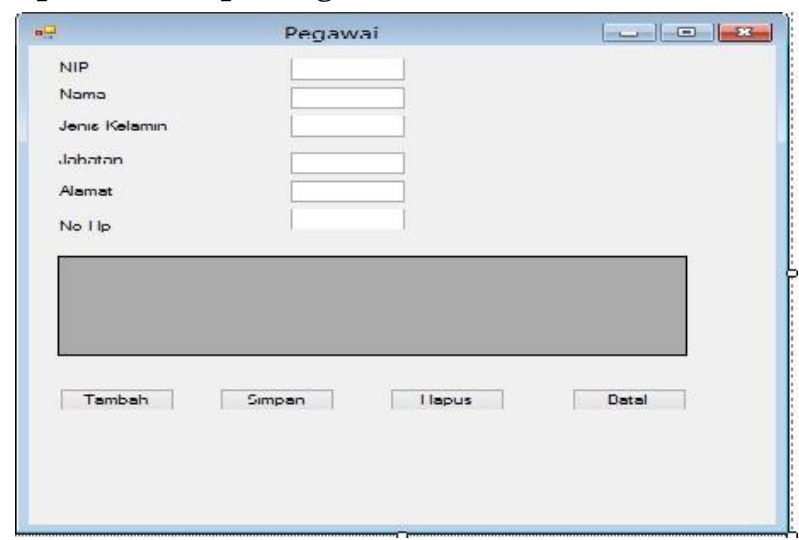

Gambar 9. Tampilan Form Pegawai

\section{Form Pembayaran}

Form Pembayaran berfungsi sebagai bukti pembayaran yang digunakan dalam pencatatan beban pengeluaran Alat Tulis Kantor (ATK) pada Kantor Urusan Agama Kecamatan Tanah Jawa kabupaten Simalungun. Tampilan form pembayaran dapat dilihat pada gambar dibawah ini:

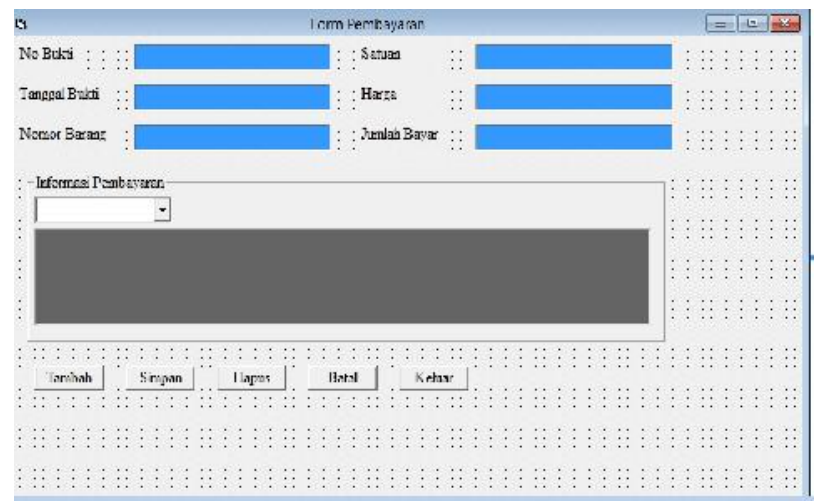

Gambar 10. Tampilan Form Pembayaran

\section{B. Rancangan Keluaran (Output)}

Rancangan keluaran merupakan rancangan laporan yang akan dihasilkan oleh sistem yang dirancang. Dibawah ini adalah 
gambaran dari rancangan keluaran (output) Sistem Pencatatan Anggaran dan Realisasi Beban Pengeluaran Alat Tulis Kantor (ATK)Pada Kantor Urusan Agama (KUA) Kecamatan Tanah Jawakabupaten Simalungun. Adapun rancangan keluaran (Output) dapat dilihat pada gambar dibawah ini:

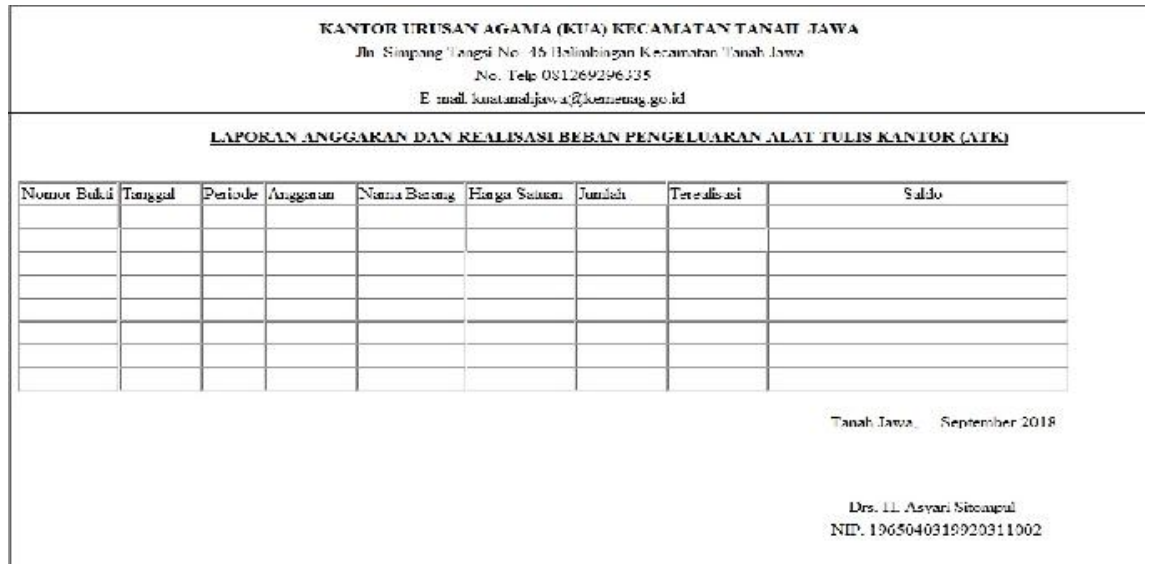

Gambar 11. Tampilan Laporan Anggaran dan Realisasi Pengeluaran Alat Tulis Kantor (ATK)

\section{Kesimpulan}

Setelah menyelesaikan perancangan Sistem Informasi Pencatatan Anggaran dan Realisasi Beban Pengeluaran Alat Tulis Kantor (ATK) pada Kantor Urusan Agama (KUA) Kecamatan Tanah Jawakabupaten Simalungun penulis mengambil beberapa kesimpulan sebagai berikut :

1. Sistem pencatatan beban pengeluaran Alat Tulis Kantor (ATK) dapat meminimalisasi kesalahan dalam input data.

2. Sistem pencatatan beban pengeluaran Alat Tulis Kantor (ATK) dapat mengotomatiskan penyimpanan data mengenai Alat Tulis Kantor (ATK).

3. Sistem ini mampu menghasilkan laporan pencatatan anggaran dan realisasi beban pengeluaran alat tulis kantor pada Kantor Urusan Agama (KUA) lebih baik.

4. Disiplin dan dedikasi yang tinggi para pegawai Kantor Urusan Agama sangat baik. 
5. Adanya sebuah aplikasi program informasi pencatatan anggaran dan realisasi beban pengeluaran Alat Tulis Kantor (ATK), sehingga mempermudah pegawai dalam mengerjakan laporannya. 


\section{Daftar Pustaka}

Afyenni, rita. 2014. "perancangan data flow diagram untuk system informasi sekolah (studi kasus pada SMA Pembangunan laboratorium UNP)." Teknoif 2 (1 april): 35-39.

Dwi puspitasari 1, cahya rahmad 2, mungki astiningrum 3. 2016. "normalisasi tabel pada basisdara relasional." Prosiding sentia 8: 340-45.

Lestari, indah, and hendri irawan. 2017. "analisis dan desain electronic customer relationship management ( e- crm ) berbasis web guna membina serta meningkatkan loyalitas penyewa studi kasus : pt . sari indah lestari ( sil ) - mall cbd ciledug." cki on spot 10(2): 47-53. https://jurnal.stikomcki.ac.id/index.php/cos/article/view/ $29 / 29$.

Nugraha, tezhar rayendra trastaronny pastika, wing wahyu winaryo, and hanif al fatta. 2018. "analisis sistem informasi akademik menggunakan domain delivery and support cobit 5 pada smkn 4 yogyakarta." 8: 21-29.

Putri, ranti eka, and randi rian putra. 2018. "perancangan aplikasi rekam medis menggunakan bahasa pemograman vb.net 2010." 5: 49-55.

Sitohang, hengki tamando. 2018. "sistem informasi pengagendaan surat berbasis web pada pengadilan tinggi medan." journal of informatic pelita nusantara 3(1): 6-9. http://ejurnal.pelitanusantara.ac.id/index.php/jipn/article/view/27 6/174.

Suhendro, dedi, dan trika aprilia. 2017. "perancangan dan implementasi realisasi anggaran pendapatan (studi kasus : pengadilan negeri kelas I B Pematangsiantar)." Seminar nasional teknologi informatika : 30-36. 